\title{
SLON MAGNETIC SEPARATOR APPLIED TO UPGRADING THE IRON CONCENTRATE
}

\author{
XIONG DAHE* \\ Ganzhou Nonferrous Metallurgy Research Institute, 36 Qingnian Rd., \\ 34100, Ganzhou, Jiangxi Province, P.R. China
}

(Received 21 December 2002; In final form 8 January 2003; Accepted 13 January 2003)

\begin{abstract}
SLon vertical ring and pulsating high gradient magnetic separator is a new generation of a highly efficient equipment for processing weakly magnetic mineral ${ }^{[1-3]}$. It possesses advantages of a large beneficiation ratio, high recovery, a matrix that cannot easily be blocked and excellent performance. In the technical reform of upgrading the iron concentrate in Qi Dashan Mineral Processing Plant of Anshan Iron and Steel Company in 2001 to 2002, ten SLon-1750 magnetic separators were successfully applied to process oxidized iron ores. The iron concentrate of the plant was upgraded from $63.22 \% \mathrm{Fe}$ to $67.11 \% \mathrm{Fe}$. The overall results of the reformed flowsheet are: the feed grade $29.84 \% \mathrm{Fe}$, the iron concentrate grade $67.11 \% \mathrm{Fe}$, the tailings grade $11.27 \% \mathrm{Fe}$, and the iron recovery $74.79 \%$, which set up a new historical record of the plant.
\end{abstract}

\section{INTRODUCTION}

Qi Dashan Mineral Processing Plant is a large oxidized iron ore processing base that belongs to the Anshan Iron and Steel Company, in Liao Ning Province, Northeast China. It processes eight million tons of oxidized iron ore and produces 2.7 million tons of the iron concentrate annually. In previous years, the grade of the iron concentrate could reach only about $63 \% \mathrm{Fe}$. In order to increase the concentrate grade, extensive test work had been done during the past several years. Finally a gravity separation-high intensity magnetic separation-reverse flotation flowsheet was chosen, in which high-intensity magnetic separation is a very important process. Through comparison of several types of high-intensity magnetic separators, ten SLon-1750 Vertical ring and Pulsating High Gradient Magnetic Separators were chosen for the high-intensity magnetic separation process.

\section{ANALYSIS OF THE QI DASHAN OXIDIZED IRON ORE}

Qi Dashan iron ore is a poor iron deposit, which consists mainly of hematite, magnetite and quartz. The crystal particle sizes of iron minerals are between 0.005 and $1.0 \mathrm{~mm}$, on average $0.05 \mathrm{~mm}$. The Quartz particle sizes are $0.085 \mathrm{~mm}$ on average. It contains very

*E-mail: gnmrims@public1.gzptt.jx.cn 
TABLE I Assay of Qi Dashan iron ore (\%)

\begin{tabular}{lcccccccc}
\hline Total $\mathrm{Fe}$ & $\mathrm{SiO}_{2}$ & $\mathrm{Al}_{2} \mathrm{O}_{3}$ & $\mathrm{CaO}$ & $\mathrm{MgO}$ & $\mathrm{P}$ & $\mathrm{S}$ & $\mathrm{K}_{2} \mathrm{O}$ & $\mathrm{Na}_{2} \mathrm{O}$ \\
\hline 29.10 & 56.10 & 0.79 & 0.19 & 0.75 & 0.04 & 0.084 & 0.18 & 0.29 \\
\hline
\end{tabular}

TABLE II Mineralogical composition of Qi Dashan iron ore (\%)

\begin{tabular}{lccccc}
\hline Mineral & Hematite & Magnetite & Mag-hematite & Silica iron & Total \\
\hline Mass (\%) & 17.13 & 4.85 & 4.46 & 2.15 & 28.00 \\
Distribution (\%) & 59.90 & 16.99 & 15.59 & 7.52 & 100.00 \\
\hline
\end{tabular}

low concentrations of harmful elements such as $\mathrm{S}$ and $\mathrm{P}$. It is thus expected that very good iron concentrate could be obtained using an efficient mineral process. Tables I and II summarise the assay and mineralogical composition of the ore.

\section{THE PREVIOUS IRON ORE PROCESSING FLOWSHEET}

The previous iron ore processing flowsheet is shown in Fig. 1.

The crushed iron ore was classified into two fractions of $-20 \mathrm{~mm}$ and $-75+20 \mathrm{~mm}$. The $-20 \mathrm{~mm}$ fraction was treated with a spiral-high intensity magnetic-flotation flowsheet. The $-75+20 \mathrm{~mm}$ fraction was treated with a roast-low intensity magnetic separation (LIMS) flowsheet. The overall results were: the feed grade $29.86 \% \mathrm{Fe}$, the iron concentrate grade $63.22 \% \mathrm{Fe}$, the tails grade $11.92 \% \mathrm{Fe}$, the iron recovery $74.04 \%$.

Problems of the previous flowsheet were that the grade of the iron concentrate could reach only about $63 \%$ and the roast process was costly, caused heavy pollution and the working conditions were difficult.

In 2000, reverse flotation was tested at the Workshop One. It demonstrated that the iron concentrate grade could reach $65 \%$ Fe.

\section{THE COMPARATIVE TEST OF SLON VPHGMS}

In early 2001, a SLon-1500 vertical ring and pulsating high-gradient magnetic separator (SLon-1500 VPHGMS) was installed at the Workshop One. A commercial comparative test was carried out between the SLon-1500 VPHGMS, a WHIMS-2000 horizontal ring high-intensity magnetic separator and a DGYC-1860 vertical ring permanent highgradient magnetic separator. This three months long comparative test, demonstrated that SLon-1500 VPHGMS was the most efficient and most reliable magnetic separator. Comparison of the results is shown in Table III.

Table III shows that with SLon-1500 as compared to DGYC-1860, grade of the magnetics and the iron recovery are 2.89 and 5.45 per cent higher. Comparison of SLon1500 with WHIMS-2000, shows that its mags grade and the iron recovery are 3.83 and 19.26 per cent higher. SLon-1500 VPHGMS not only achieved much better beneficiation results, but also it possesses advantages of a higher operating ratio, higher ore throughput capacity, no matrix blockage problem (matrix is always kept clean) and it is much easier to maintain than the other types of magnetic separators. 


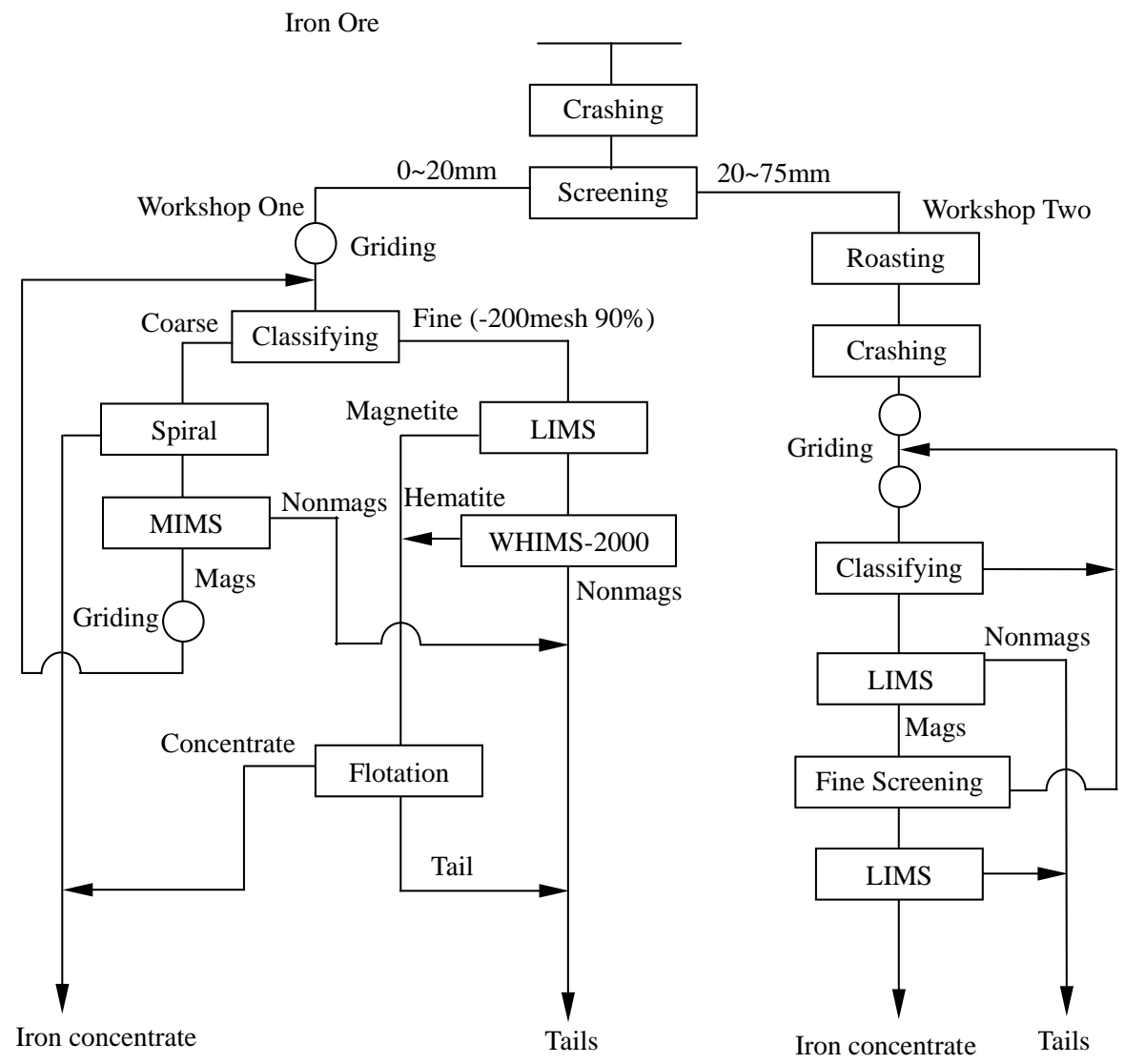

FIGURE 1 The previous flowsheet of Qi Dashan Mineral Processing Plant. LIMS - low intensity magnetic separation; MIMS - mid intensity magnetic separation; WHIMS - wet high intensity magnetic separation.

TABLE III Comparison results of three types of magnetic separators

\begin{tabular}{lcccccc}
\hline Magnetic separator & $\begin{array}{c}\text { Ore throughput } \\
(\mathrm{t} / \mathrm{h})\end{array}$ & $\begin{array}{c}\text { Feed grade } \\
(\mathrm{Fe} \%)\end{array}$ & $\begin{array}{c}\text { Mags grade } \\
(\mathrm{Fe} \%)\end{array}$ & $\begin{array}{c}\text { Tails grade } \\
(\mathrm{Fe} \%)\end{array}$ & $\begin{array}{c}\text { Iron recovery } \\
(\%)\end{array}$ & $\begin{array}{r}\text { Operating } \\
\text { ratio }(\%)\end{array}$ \\
\hline SLon-1500 & 35.53 & 14.25 & 27.45 & 7.80 & 63.23 & 99.03 \\
DGYC-1860 & 31.19 & 15.19 & 24.56 & 9.98 & 57.78 & 98.66 \\
WHIMS-2000 & 36.01 & 14.33 & 23.62 & 10.95 & 43.97 & 89.50 \\
SLon-1500 vs & +4.34 & -0.94 & +2.89 & -2.18 & +5.45 & +0.37 \\
$\quad$ DGYC-1860 & & & & & & +3.15 \\
SLon-1500 vs & -0.48 & -0.08 & +3.83 & & & +9.53 \\
$\quad$ WHIMS-2000 & & & & & & \\
\hline
\end{tabular}

\section{THE FLOWSHEET INNOVATION}

In 2001 to 2002, a technical reform was carried out in Qi Dashan Mineral Processing Plant. The roast LIMS flowsheet in the Workshop Two had been changed into a spiral-SLon VPHGMS-flotation flowsheet, in which six SLon-1750 VPHGMS were 
installed. Additional four SLon-1750 VPHGMS were installed in the Workshop One to replace the previous five WHIMS-2000 high-intensity magnetic separators. The entire direct flotation was changed into reverse flotation. The new principle flowsheet is shown in Fig. 2 and the installation of SLon separators is shown in Fig. 3.

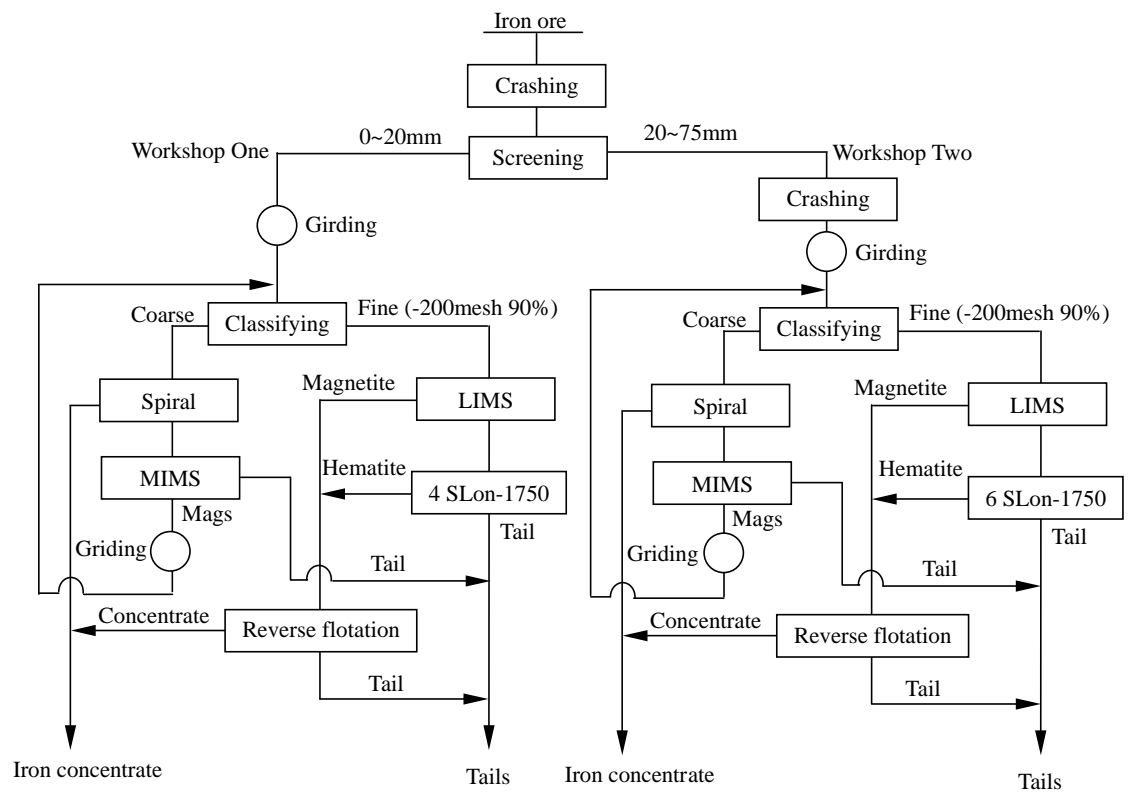

FIGURE 2 The novel flowsheet of Qi Dashan Mineral Processing Plant. LIMS - low intensity magnetic separation; MIMS - mid intensity magnetic separation; SLon-1750 - SLon-1750 VPHGMS.

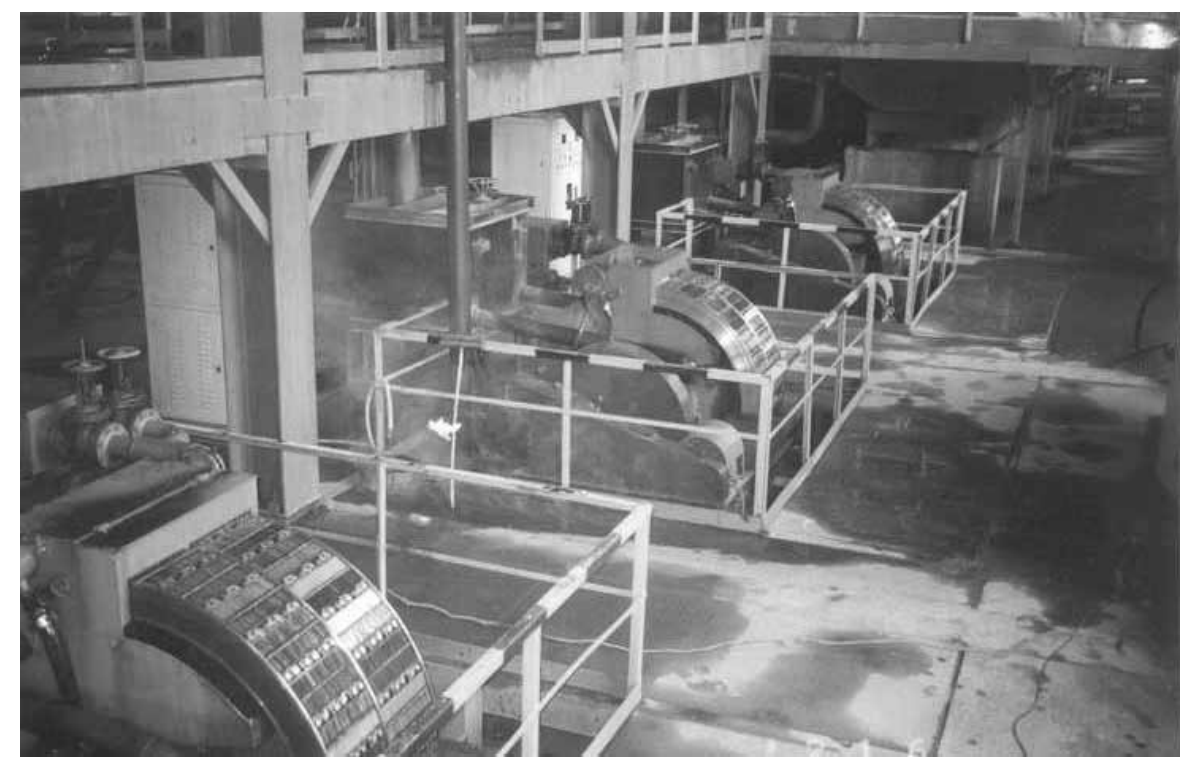

FIGURE 3 Ten SLon-1750 vertical ring and pulsating high-gradient magnetic separators as applied in the new flowsheet of Qi Dashan Mineral Processing Plant. 
The results of the new flowsheet as compared to the previous flowsheet are shown in Table IV.

Table IV shows that the new flowsheet achieves very good quality iron concentrate, the grade of which reaches $67.11 \%$, which is much higher than $63.22 \%$, achieved by the previous flowsheet.

As the novel flowsheets of the Workshop One and the Workshop Two are similar, let us have a look at the details of the new flowsheet of the Workshop Two.

As shown in Fig. 4, the $-75+20 \mathrm{~mm}$ iron ore is crushed and ground to $60 \%-200$ mesh by a primary ball mill and classified by a cyclone to two fractions. The coarse fraction is treated by spirals and MIMS (medium-intensity magnetic separator). The spirals remove part of the coarse iron concentrate and the MIMS discharge part of the coarse tailings. The spiral middlings and the mags of MIMS are sent to the secondary ball mill and then returned to the cyclone feed. The fine fraction (90\%-200 mesh) is treated by LIMS (low-intensity magnetic separator) to concentrate magnetite, then by six SLon-1750 VPHGMS concentrate hematite and discharge part of the fine tailings. The mags of LIMS and SLon-1750 are mixed and further cleaned by reverse flotation. The spiral concentrate and flotation concentrate are joined as the final concentrate. The MIMS tailings, SLon-1750 tailings and flotation tailings are joined as the final tailings.

Advantages of this flowsheet are the following: the spiral takes out most of the liberated coarse iron concentrate and the MIMS discharges part of the coarse tailings, which greatly reduces the feed into the secondary ball mill (10 primary ball mills to 3 secondly ball mills). The tailings grade of 6 SLon-1750 VPHGMS only is $8.91 \%$, the mass ratio of the tailings to the feed of SLon- 1750 is $73.31 \%$ and $31.31 \%$ to the feed of the flowsheet, $47.45 \%$ to the total tailings of the flowsheet. Because the tailings grade of SLon-1750 is very low and the proportion is relatively large, SLon-1750 not only effectively controlled the fine fraction tailings, but also guaranteed the high iron recovery of the total flowsheet. Reverse flotation can achieve good quality of the fine concentrate.

\section{CONCLUSIONS}

Most Chinese iron ores are very poor. To get good quality iron concentrate, it is necessary to apply efficient equipment and advanced technology to treat iron ores of low grade.

Qi Dashan Mineral Processing Plant is a major iron ore concentrator of the Anshan Iron and Steel Company. The grade of its mined iron ore is only about $30 \% \mathrm{Fe}$.

TABLE IV Results of a new flowsheet $v$ s previous flowsheet

\begin{tabular}{lccccccc}
\hline & & $\begin{array}{c}\text { Feed } \\
\text { grade }\end{array}$ & $\begin{array}{c}\text { Concentrate } \\
\text { grade } \\
(\mathrm{Fe} \%)\end{array}$ & $\begin{array}{c}\text { Tails } \\
\text { grade }\end{array}$ & $\begin{array}{c}\text { Concentrate } \\
\text { mass ratio } \\
(\mathrm{Fe})\end{array}$ & $\begin{array}{c}\text { Iron } \\
\text { recovery } \\
(\%)\end{array}$ & $\begin{array}{c}\text { Ore } \\
\text { throughput } \\
\text { (million tons/year) }\end{array}$ \\
\hline \multirow{2}{*}{ New flowsheet } & Workshop One & 29.50 & 67.00 & 11.50 & 32.43 & 73.66 & 3.8 \\
& Workshop Two & 30.15 & 67.20 & 11.05 & 34.02 & 75.82 & 4.2 \\
Previous flowsheet & Total & 29.84 & 67.11 & 11.27 & 33.26 & 74.79 & 8.0 \\
& Workshop One & 29.50 & 63.47 & 12.50 & 33.35 & 71.76 & 3.8 \\
& Workshop Two & 30.19 & 63.02 & 11.36 & 36.45 & 76.09 & 4.2 \\
New flowsheet $v s$ previous flowsheet & 29.86 & 63.22 & 11.92 & 34.97 & 74.04 & 8.0 \\
\hline
\end{tabular}




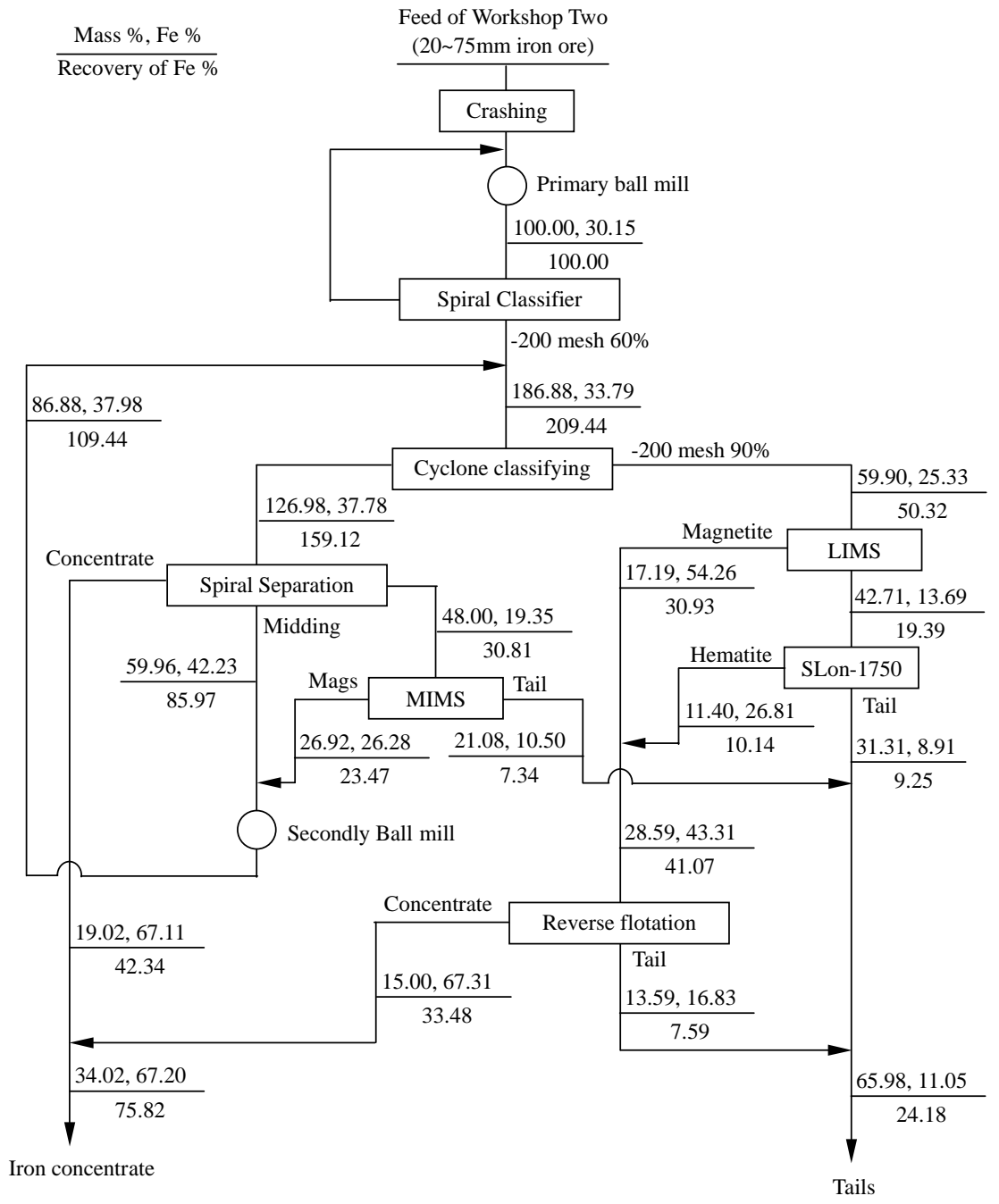

FIGURE 4 The technical data of the novel flowsheet of Qi Dashan Workshop Two.

Its previous oxidized iron processing flowsheet can only obtain iron concentrate with the grade of $63.22 \% \mathrm{Fe}$. In recent years, the plant developed a novel flowsheet consisting of spiral-SLon VPHGMS-reverse flotation, which replaced the previous flowsheet of coal gas roasting-low-intensity magnetic separation. Its iron concentrate grade reached $67.11 \% \mathrm{Fe}$. The iron concentrate quality has been greatly upgraded and the processing cost has also been reduced.

Ten SLon-1750 vertical ring and pulsating high gradient magnetic separators (SLon1750 VPHGMS) are installed at the plant. Their successful application in the 8 million oxidized iron ore processing plant demonstrated that they are very efficient and reliable. They successfully control the tailings of the fine fraction. The iron recovery of the plant reaches $74.79 \%$. The average iron concentrate grade and recovery are expected to reach $67.20 \% \mathrm{Fe}$ and $76.80 \%$ respectively as the flowsheet is being improved in the coming years. 


\section{References}

[1] Xiong Dahe (1997). Development and commercial test of SLon-2000 vertical ring and pulsating high gradient magnetic separator. Magn. Electr. Sep., 8, 89-100.

[2] Xiong Dahe et al. (1998). New technology of pulsating high gradient magnetic separation. Int. J. Miner. Process, 54, 111-127.

[3] Xiong Dahe (2002). A large scale application of SLon magnetic separator in Meishan Iron Ore Mine. Magn. Electr. Sep., 11, 1-8. 